\title{
A False Sense of Security: Lesbian, Gay, Bisexual, and Transgender (LGBT) Surrogate Health Care Decision-Making Rights
}

\author{
Lance Wablert, PhD, and Autumn Fiester, PhD
}

This article addresses the timely and ethically problematic issue of surrogate decision-making rights for lesbian, gay, bisexual, and transgender (LGBT) patients and their families in the American health care system. Despite multiple pro-LGBT recommendations that have been released in recent years by the Obama administration, the Institute of Medicine, and the US Department of Health and Human Services, such initiatives, while laudable, also have unfortunately occasioned a "false sense of security" for many LGBT patients, their families, and their caregivers. In particular, new regulations on surrogate decision making merely invoke a sense of universal patient rights rather than actually generating them. Therefore, it is imperative that primary care physicians urge all LGBT patients to take proactive steps to protect themselves and their loved ones by naming proxy decision makers well before the crises that would necessitate such decisions. (J Am Board Fam Med 2013;26:802-804.)

Keywords: Bisexuals, End of Life Care, Gays, Lesbians, Medical Ethics, Patient Education, Transgenders

The recent June 2013 decision of the US Supreme Court to repeal the federal Defense of Marriage Act has brought considerable attention and support to the equal rights efforts of same-sex couples. ${ }^{1,2}$ President Barack Obama's second term brings with it the opportunity to build on this milestone and secure essential health care rights for lesbian, gay, bisexual, and transgender (LGBT) people introduced during his first administration. In the past 2 years there has been a cascade of initiatives that address the health care concerns of persons who are LGBT. These include the 2010 Presidential Memorandum on Hospital Visitation, which asked for greater sensitivity for all families in medical "moments of pain and anxiety"; cent calls for more inclusion of LGBT issues in

This article was externally peer reviewed.

Submitted 24 April 2013; revised 17 July 2013; accepted 24 July 2013.

From the Department of Medical Ethics and Health Policy, Perelman School of Medicine, University of Pennsylvania, Philadelphia, PA.

Funding: none.

Conflict of interest: none declared.

Corresponding author: Autumn Fiester, $\mathrm{PhD}$, Department of Medical Ethics and Health Policy, Perelman School of Medicine, University of Pennsylvania, 3401 Market Street, Suite 320,Philadelphia,PA19104-3319(E-mail: fiester@mail. med.upenn.edu). medical school curricula ${ }^{4}$; the landmark 2011 Institute of Medicine report on the state of LGBT health care, which demanded greater and more regular study "to understand the health needs of LGBT populations"; a 2012 report by the US Department of Health and Human Services calling for increased programmatic and research funding related to LGBT health ${ }^{6}$; and the LGBT nondiscrimination and cultural competency training provisions in the recently upheld Affordable Care Act of 2012. Such heightened attention clearly demonstrates the admirable interest of many American health care-related institutions in the clinical treatment of LGBT persons.

With the recent flurry of such well-intentioned initiatives, however, LGBT patients are vulnerable to being misled into believing that their rights extend further than they do, giving them a false sense of security with regard to specific arenas of medical practice. One area particularly vulnerable to this misinterpretation is LGBT surrogate decision making. In the wake of multiple bold proclamations, many LGBT patients mistakenly believe that they have been granted additional federal rights to make end-of-life decisions for their loved ones when, in fact, they have not.

The most recent source of this serious misunderstanding has been President Obama's laudatory Hos- 
pital Visitation Memorandum of April 2010, which challenged the discrimination against LGBT patients who have documented visitation preferences, advance directives, or health care proxies. The memorandum requires federally funded hospitals (including those receiving Medicare and Medicaid funds) to respect the stated visitation preferences of LGBT patients and to honor their documentation regarding decision making by a surrogate, which often are disregarded or ignored. Although the Obama policy speaks to the visitation and surrogate decision making rights of all families, it specifically invokes LGBT patients by stating: "uniquely affected are gay and lesbian Americans who are often barred from the bedside of the partners with whom they may have spent decades of their lives-unable to be there for the person they love, and unable to act as a legal surrogate if their partner is incapacitated." In fact, it was the 2007 case of lesbian Janice Langbehn, who was partners with Lisa Pond for 18 years and was Lisa's legally secured health care proxy, that inspired the Obama policy. ${ }^{7}$ When Ms. Pond suffered a brain aneurysm, the hospital denied Ms. Langbehn both visitation and surrogate decision-making rights. The Obama memorandum now enforces hospital visitation and surrogate decision making rights that are already legally protected in certain jurisdictions, such as the Durable Power of Attorney for Health Care Ms. Langbehn had, ${ }^{8}$ but it does not grant LGBT families any additional rights.

The potential perils are most grave with regard to decision making by a surrogate. ' LGBT partnerships that lack either legal documentation or the "next of kin" status granted through a civil union or marriage in states that recognize such partnerships are no better off now than they were before the Obama memorandum. Accordingly, the trail-blazing prose of the Obama memorandum quoted above can mislead LGBT families, couples, and patients.

Take, for example, the headline on the American Civil Liberties Union website on the day the memorandum was issued: "New Rules Grant Greater Medical Rights for Same-Sex Partners." ${ }^{10}$ In the lead paragraph, the American Civil Liberties Union immodestly states, "The order will allow for samesex partners to have the same rights as other immediate family members." This is, in fact, not true, and yet the memorandum was widely hailed as extending LGBT partner rights in both the gay and mainstream media. The ethical dilemma here is not the Obama memorandum's limited reach but that many LGBT patients and their advocates might assume protection when there is none. This misreading is understandable: Unless read closely and in context, the document quite easily encourages one to infer more rights than the policy actually provides. It hints at new rights but does not actually issue any.

Many LGBT partners and families find themselves in circumstances parallel to those of Ms. Langbehn and Ms. Pond, caught off guard with an unexpected health care crisis and surprised to find that their years of domestic partnership do not afford them the default status of decision maker they thought they had. Since most LGBT partnerships are not formalized because of the long (and continuing) history of being barred from the legal institutions available to heterosexual couples, LGBT patients face a significant—and disproportionate-risk that someone other than their life partner will make critical end-of-life decisions for them if they become incapacitated. ${ }^{11}$ These decisions can quite often conflict with a same-sex couple's deeply held values and preferences.

Such differential treatment is not new. Second-class citizenry in the medical arena has been a long-standing condition for LGBT patients. ${ }^{12-15}$ They historically have been pathologized, ostracized, marginalized, or disempowered by medicine in countless ways. What is new is the potential for the dangerous belief that recent pro-LGBT policies and initiatives completely protect such patients and their families when much work still needs to be done to secure universal patient protections and rights. If the Obama Visitation Memorandum was pitched in a celebratory tone, it thereby also masks the fact that it merely bolsters the status quo. While it is an LGBT-affirming policy, it also fails to benefit many LGBT patients in that it can unintentionally mislead them to believe that they are living in an era that has overcome the painful histories of pathology and stigma.

The ultimate antidote to this false sense of security is, of course, real security. With the re-election of President Obama, his second administration needs to establish substantive legal rights that can protect all LGBT families where there are currently mere promissory notes. As policies are being developed and implemented, policymakers are obligated to be more measured in announcing changes so that they do not overstate the ground being gained. LGBT-affirming policies are counterproductive if they exaggerate health care rights, lulling patients into complacency when they should be taking vital steps to truly protect themselves. 
Given the current state of US health laws and policies, ${ }^{16-18}$ with progress and faux progress in a delicate dance, it is imperative that clinicians urge all LGBT patients to take proactive steps to protect themselves and their loved ones. Advocacy organizations like the Lambda Legal Defense \& Education Fund ${ }^{19}$ and the Human Rights Campaign ${ }^{20}$ have led this charge, clarifying the health care rights that Obama's visitation policy gestures toward but does not guarantee. ${ }^{21,22}$ Individual health care practitioners also need to assist LGBT patients in articulating their wishes and naming proxy decision makers well before the crises occur that would necessitate such decisions. Only one fourth of LGBT patients have discussed their end-of-life preferences with their primary care provider. ${ }^{23}$ Primary care providers need to urge all their LGBT patients to secure a Durable Power of Attorney for Health Care, the most protective legal safeguard for effectuating a patient's health care preferences. A recent study indicates that only 2 of 5 LGBT patients have taken this important step. ${ }^{24}$ While important for all patients, it is critical that a discussion about health care proxies with self-identified LGBT patients be included in routine primary care practice.

\section{References}

1. Liptak, A. Supreme Court bolsters gay marriage with two major rulings. New York Times, June 26, 2013. Available from: http://www.nytimes.com/2013/06/ 27/us/politics/supreme-court-gay-marriage.html? pagewanted=all\&_r=0. Accessed September 17, 2013.

2. Unites States Supreme Court, section 3 (1 U.S.C. $\$$ 7), June 26, 2013.

3. Obama B. Presidential memorandum-hospital visitation. Washington, D.C.: The White House, Office of the Press Secretary; 2010. Available from: http:// www.whitehouse.gov/the-press-office/presidentialmemorandum-hospital-visitation. Accessed September 17, 2013.

4. Obedin-Maliver J, Goldsmith ES, Stewart L, MD. Lesbian, gay, bisexual, and transgender-related content in undergraduate medical education. JAMA 2011;306:971-7.

5. The health of lesbian, gay, bisexual, and transgender people: building a foundation for better understanding. Washington, D.C.: Institute of Medicine, 2011. Available from: http://www.iom.edu/Reports/2011/The-Healthof-Lesbian-Gay-Bisexual-and-Transgender-People. aspx. Accessed September 17, 2013.

6. HHS LGBT Issues Coordinating Committee 2012 report. Washington, D.C.: U.S Department of Health and Human Services, 2012. Available from: (http:// www.hhs.gov/secretary/about/lgbthealth_objectives_ 2012.html\#intro. Accessed September 17, 2013.
7. Parker-Pope T. Kept from a dying partner's bedside. New York Times, May 19, 2009. Available from: http:// www.nytimes.com/2009/05/19/health/19well.html?_r= 0\&pagewanted=print. Accessed July 13, 2013.

8. Conlon A, Aldredge PA. Department of health and human services changes: Implications for hospital social workers. Health Soc Work 2013;38:19-27.

9. Wahlert L, Fiester A. Mediation and surrogate decision-making for LGBTQ families in the absence of an advance directive. J Bioeth Inq 2012;9:365-7.

10. New rules grant greater medical rights for same-sex partners. New York: American Civil Liberties Union; 2010. Available from: http://www.aclu.org/ lgbt-rights/new-rules-grant-greater-medical-rightssame-sex-partners. Accessed September 17, 2013.

11. Buckey JW, Browning CN. Factors affecting the LGBT population when choosing a surrogate decision maker. J Soc Serv Res 2013;39:233-52.

12. Harding R, Epiphanious E, Chidgey-Clark, J. Needs, experiences, and preferences of sexual minorities for end-of-life care and palliative care: a systematic review. J Palliat Med 2012;15:602-12.

13. Keepnews DM. Lesbian, gay, bisexual, and transgender health issue and nursing: moving toward an agenda. ANS Adv Nurs Sci 2011;34:163-70.

14. Mollon L. The forgotten minorities: health disparities of the lesbian, gay, bisexual, and transgendered communities. J Health Care Poor Underserved 2012;23:1-6.

15. Simone MJ, Appelbaum JS. Addressing the needs of older lesbian, gay, bisexual, and transgender adults. Clin Geriatr 2011;19:38-45.

16. Bailey R. Health law: The LGBT community, health policy, and the law. Virtual Mentor 2010;12: 658-62.

17. Hernandez JO. Gay rights one baby-step at a time: protecting hospital visitation rights for same-sex partners while the lack of surrogacy rights lingers. J Bioeth Inq 2012;9:361-3.

18. Mohanty A. Medical rights for same-sex couples and rainbow families. Richmond J Law Public Int 2010; 13:367-83.

19. Lamda Legal [homepage]. Available from: http:// www.lambdalegal.org/. Accessed July 13, 2013.

20. Human Rights Campaign [homepage]. Available from: http://www.hrc.org/. Accessed July 13, 2013.

21. Heathcare equality index. Washington, D.C.: Human Rights Campaign. Available from: http://www.hrc.org/ hei\#.UeHdX23hcUo/. Accessed July 13, 2013.

22. Health care fairness. New York: Lambda Legal. Available from: http://www.lambdalegal.org/issues/ health-care-fairness. Accessed July 13, 2013.

23. Stein GL, Bonuck, KA. Attitudes on end-of-life care and advance care planning in the lesbian and gay community. J Palliat Med 2001;4:173-90.

24. MetLife. Still out, still aging: the MetLife study of lesbian, gay, bisexual, and transgender baby boomers. Westport, CT: MetLife Mature Market Institute, 2010. 